\title{
Simulation of Single Stage LNA Based on Ladder Matching Networks for WiMAX Application
}

\author{
Abu Bakar Ibrahim and Ahmad Zamzuri Mohamad Ali
}

\begin{abstract}
This paper presents a simulation of single stage LNA based on ladder matching networks for WiMAX application. Wireless communication is a type of telecommunication that available for transmitting the large amounts of data, voice and video over long distance using a different frequency. Low Noise Amplifier is located at the first block of receiver system, which makes it one of the important parts to amplified the signal. This project is to design a Low Noise Amplifier for wireless Application that will work at 5.8 GHz using high-performance low noise superHEMT transistor FHX76LP manufactured by Eudyna Technologies. From the simulaton result the low noise amplifier produced gain $\left(S_{21}\right)$ of $17.2 \mathrm{~dB}$ and return loss $\left(S_{12}\right)$ of -19.9. The input reflection $\left(S_{11}\right)$ and output return loss $\left(S_{22}\right)$ are $-19.9 \mathrm{~dB}$ and $-19.6 \mathrm{~dB}$ respectively. While, the noise figure is $0.914 \mathrm{~dB}$.
\end{abstract}

Index Terms-LNA, radio frequency, ladder matching network.

\section{INTRODUCTION}

Wireless Communication System is rapidly becoming one of the fastest growing segments of the communication industry. Incrasing the data rate, expending the coverage area and accommodating more compenents on the same chip are crucial motivation behind the occuring of different generation of wireless communication systems [1]. Developments in the wireless industry, internet access without borders and increasing demand for high data rate wireless digital communication moving us toward the optimal development of communication technology. Wireless communication is a technology that plays an important role in the development of the current transformation.

At present, the modern communication system is based on Radio Frequency (RF) transmission are one of the greatest examples of this challenging demand. These systems, present in almost all equipment used in daily life such as mobile phones, notebooks, wireless sensor, among other require an increasing versatility and ability to store data, huge transmission rates of information and saiz reduction. Therefore, new technology in communication has been built to meet current demands, for example of wireless communication devices is mobile such as mobile phones pagers, wireless local area network (WLAN), Worldwide Interoperability for Microwave Access (WiMAX), Bluetooth and global positioning system (GPS) phones and ultra wideband (UWB) technologies are all examples of portable

Manuscript received October 10, 2015; revised March 5, 2016.

Abu Bakar Ibrahim and Ahmad Zamzuri Mohamad Ali are with the Sultan Idris Education University, Malaysia (e-mail: bakar@fskik.upsi.edu.my, zamzuri@fskik.upsi.edu.my). wireless communication devices [1]

Wireless communication is a type of telecommunication that available for transmitting the large amounts of data, voice and video over long distance using a different frequency. This is also considered with several technologies with transmission rates above the fastest speed available over a telephone line. In most high-frequency communication system, Gallium-Arsenide (GaAs) metal-semiconductor-field-effect transistor (MESFET) and heterojunction bipolar transistor (HBT) show their strong presence in RF product because they give high performance on output power [2].

Usually the first active signal processing block after the antenna is Low noise amplifier (LNA). The amplitude of the received signal at the input LNA may vary from few $\mathrm{nV}$ that is less than $-130 \mathrm{dBm}$ for GPS signals to tens $\mathrm{mV}$. The LNA should be capable of amplifying all these signals without causing any significant distortion. This requires that very little noise from the LNA be introduced to the entire receiver [3].

Fig. 1 is the basic to the structure of the RF receiver. As the first block is active after the antenna, LNA has the advantage of high and should be able to reduce noise in the system. The signal received from the antenna will be screened and will be amplified by the LNA and will be sent to the bandpass with a local oscillator. After the demodulated, modulated signal will be used for analog-to-digital (ADC) that converts analog signals to digital signals. Digital signal processing (DSP) will process the digital signal produces by an analog-to-digital (ADC). Therefore, a lot can affect the LNA parameter sensitivity and performance of the overall receiver noise.

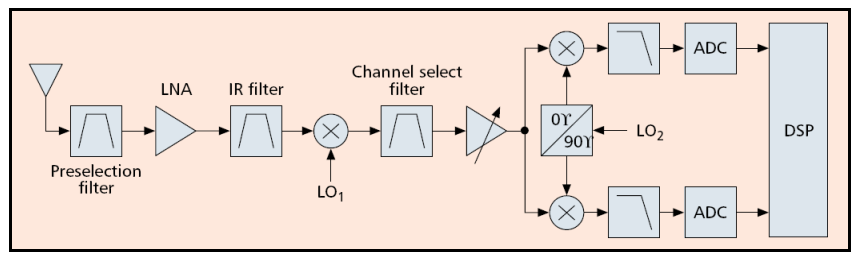

Fig. 1. Structure of the RF receiver.

The LNA is one of the most important components of in communication receiver. The LNA requires amplifying the received signal with sufficient gain and if possible having a little additional noise. Noise Figure has a major impact on deciding the system's overall in LNA. An LNA can be designed with different circuit topologies; each method proposes to accommodate a wide bandwidth through input and output impedance matching. Such as, shunt-series feedback topology is having broadband behavior as well as good input and output matching characteristics. A capacitor is used in series with feedback to avoid the effect of the output voltage at the optimum basing point in IV curve.

Therefore the higher gain is achieved when the power 
consumption is low. An inductive load which improves the output noise performance as well as overcomes the gain degradation at higher frequencies is employed. Another inductor is added in series with feedback to give an additional gain at higher frequencies. The inductive degenerated topology had a superior performance as compared to its common gate. Also this topology provides simultaneous input matching and minimum Noise Figure [1], [2].

\section{THEORETICAL ASPECTS}

Initially, when designing an amplifier, the input and output matching network are consider to achieve the required stability, small signal gain, and bandwidth. Super high frequency amplifier is a typical active circuit used to amplify the amplitude of RF signal. Basic concept and consideration in design of super high frequency amplifier is presented in this paper. The LNA designed, the formula and equation were referred to [4]. Fig. 2, shows a typical single stage amplifier including input output matching networks. The basic concept of high frequency amplifier design is to match input/output of a transistor at high frequencies using S-parameters frequency characteristics at a specific DC-bias point with source impedance and load impedance. Input/output matching circuit is essential to reduce the unwanted reflection of signal and to improve efficiency of the transmission from source to load [4], [5].

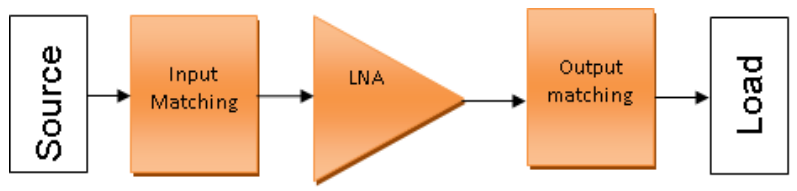

Fig. 2. Typical amplifier design.

\section{A. Power Gain}

Several power gains were defined in order to understand operation of super high frequency amplifier. Fig. 3, show that power gains of 2-port circuit network with power impedance or load impedance at power amplifier. The power amplifiers represented with scattering coefficients are classified into Operating Power Gain, Transducer Power Gain and Available Power Gain [4], [5].

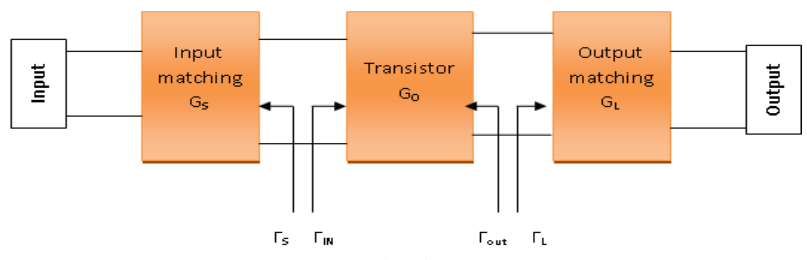

Fig. 3. I/O circuit of 2-port network.

\section{B. Operating Power Gain}

Operating power gain is the ratio of load power $\left(P_{L}\right)$ delivered to the load $\left(Z_{L}\right)$ to input power $\left(P_{\text {in }}\right)$ supplied to 2-port network. Power delivered to the load is the difference between the power reflected at the output port and the input power, and power supplied to 2-port network is the difference between the input power at the input port and the reflected power. Therefore, Operating Power Gain is represented by

$$
\begin{aligned}
& G_{P}=\frac{\text { Power delivered to the load }}{\text { Power supplied to the amplifier }} \\
& =\frac{P_{L}}{P_{\text {in }}}=\frac{1}{1-\left|\Gamma_{\text {in }}\right|^{2}}\left|S_{21}\right|^{2} \frac{1-\left|\Gamma_{L}\right|^{2}}{\left|1-S_{22} \Gamma_{L}\right|^{2}}
\end{aligned}
$$

where, $\Gamma_{\text {in }}$ indicates reflection coefficient of load at the input port of 2-port network and $\Gamma_{s}$ is reflection coefficient of power supplied to the input port.

\section{Transducer Power Gain}

Transducer Power Gain is the ratio of $P_{a v s}$, maximum power available from source to $P_{L}$, power delivered to the load. As maximum power is obtained when input impedance of circuit network is equal to conjugate complex number of power impedance, if $\Gamma_{\text {in }}=\Gamma_{s}$, transducer power gain is represented by

$$
\begin{aligned}
& G_{T}=\frac{\text { Power delivered to the load }}{\text { Power available from the source }} \\
& =\frac{P_{L}}{P_{\text {avs }}}=\frac{\left|S_{21}\right|^{2}\left(1-\left|\Gamma_{S}\right|^{2}\right)\left(1-\left|\Gamma_{L}\right|^{2}\right)}{\left|\left(1-S_{11} \Gamma_{S}\right)\left(1-S_{22} \Gamma_{L}\right)-\left(S_{12} S_{21} \Gamma_{S} \Gamma_{L}\right)\right|^{2}}
\end{aligned}
$$

where, $\Gamma_{L}$ indicates load reflection coefficient.

\section{Available Power Gain}

Available Power Gain, $G_{A}$ is the ratio of $P_{a v s}$, power available from the source, to $P_{a v n}$, power available from 2-port network, that is, $G_{A}=\frac{P_{a v n}}{P_{a v s}}$. Power gain is $P_{a v n}$ when $\Gamma_{\text {in }}=\Gamma_{s}^{*}$. Therefore Available Power Gain is given by:

$$
\begin{aligned}
G_{A} & =\frac{\text { Power available from the amplifier }}{\text { Power available from the source }} \\
& =\frac{P_{a v n}}{P_{a v s}}=\frac{1-\left|\Gamma_{S}\right|^{2}}{\left|1-S_{11} \Gamma_{S}\right|^{2}}\left|S_{21}\right|^{2} \frac{1}{\left|1-S_{22} \Gamma_{L}\right|^{2}}
\end{aligned}
$$

That is, the above formula indicates power gain when input and output are matched [5].

\section{E. Noise Figure}

Signals and noises applied to the input port of amplifier were amplified by the gain of the amplifier and noise of amplifier itself is added to the output. Therefore, SNR (Signal to Noise Ratio) of the output port is smaller than that of the input port. The ratio of SNR of input port to that of output port is referred to as noise figure and is larger than $1 \mathrm{~dB}$. Typically, noise figure of 2-port transistor has a minimum value at the specified admittance given by formula:

$$
F=F_{\min }+\frac{R_{N}}{G_{S}}\left|Y_{s}-Y_{o p t}\right|^{2}
$$

where, $R_{N}$ is the equivalent noise resistance of two ports. $F_{\min }$ is the minimum noise factor obtained by adjusting tuners at the input of the amplifier. The normalized presented by the tuners at $F_{\min }$ is $Y_{o p t}$. With $Y_{s}=Y_{s} / Z_{o}$ being the actual 
normalized admittance.

For low noise transistors, manufactures usually provide $F_{\text {min }}, R_{N}, Y_{o p t}$ by frequencies. $N$ defined by formula for desired noise figure:

$$
N=\frac{\left|\Gamma_{s}-\Gamma_{o p t}\right|^{2}}{1-\left|\Gamma_{S}\right|^{2}}=\frac{F-F_{\min }}{4 R_{N} / Z_{0}}\left|1+\Gamma_{o p t}\right|^{2}
$$

\section{F. Condition for Matching}

The scattering coefficients of transistor were determined. The only flexibility permitted to the designer is the input/output matching circuit. The input circuit should match to the source and the output circuit should match to the load in order to deliver maximum power to the load. After stability of active device is demand, input/output matching circuits should be designed so that reflection coefficient of each port is correlated with conjugate complex number as given below [6]:

$$
\begin{gathered}
\Gamma_{\mathrm{IN}}=\Gamma_{S}{ }^{*}=S_{11}+\frac{S_{12} S_{21} \Gamma_{L}}{1-S_{22} \Gamma_{L}} \\
\Gamma_{\text {oUT }}=\Gamma_{L}^{*}=S_{22}+\frac{S_{12} S_{21} \Gamma_{S}}{1-S_{11} \Gamma_{S}}
\end{gathered}
$$

The noise figure of the first stage of the receiver overrules noise figure of the whole system. To get a minimum noise figure using a transistor, power reflection coefficient should match with $\Gamma_{o p t}$ and load reflection coefficient should match with $\Gamma_{\text {out }}^{*}$

$$
\begin{gathered}
\Gamma_{s}=\Gamma_{\text {opt }} \\
\Gamma_{L}=\Gamma_{\text {out }}^{*}=\left(S_{22}+\frac{S_{12} S_{21} \Gamma_{s}}{1-S_{11} \Gamma_{s}}\right)
\end{gathered}
$$

\section{DESIGN OF LNA}

The Fig. 4(a) is the matching network for input matching network port, while the Fig. 4(b) is the matching network uses for output port respectively to provider the good performance in term of stability, power gain and S-Parameter. The passive elements in the input matching network are $L_{1}, L_{2}, C_{1}$ and $C_{2}$. A ladder matching network is used to match the input impedance. Using Smith Chart matching techniques, the component values are shown in Table I.

The goals in LNA design are to maximize its gain and minimize its noise figure with sufficient linearity and impedance matching [7], [8]. In order to achieved the key demands for WiMAX receiver characteristics, a LNA is designed should be met are the noise figure less than $3 \mathrm{~dB}$ and power gain should be more than $15 \mathrm{~dB}$. Also good input and output impedance matching to achieved the s-parameter values.

Fig. 5(a) shows, the complete schematic circuit of $5.8 \mathrm{GHz}$ a single stage of Low noise amplifier. It was simulated using the same software to fine and further optimized for a better performance. For purpose of fabrication, the inductances and capacitances need to be converted to microstrip layout. Fig. 5(b) shows, the complete schematic layout. The Duriod 5880 TYL-0200 was selected for fabricate. The LNA parameter is shown in a Table I.

\begin{tabular}{lll}
\multicolumn{3}{c}{ TABLE I: LNA PARAMETERS } \\
\hline Component & Width $(\mathrm{mm})$ & Length $(\mathrm{mm})$ \\
\hline $\mathrm{TL}_{1}=3.24 \mathrm{nH}$ & $W=1.554$ & $L=15.25$ \\
\hline $\mathrm{TL} 2=1.23 \mathrm{nH}$ & $W=1.554$ & $L=6.07$ \\
\hline $\mathrm{TL} 3=0.40 \mathrm{pF}$ & $W=1.554$ & $L=12.44$ \\
\hline $\mathrm{TL} 3=0.24 \mathrm{pF}$ & $W=1.554$ & $L=10.44$ \\
\hline $\mathrm{TL} 4=1.55 \mathrm{nH}$ & $W=1.554$ & $L=7.64$ \\
\hline $\mathrm{TL} 5=1.62 \mathrm{nH}$ & $W=1.554$ & $L=7.98$ \\
\hline $\mathrm{TL} 6=0.43 \mathrm{pF}$ & $W=1.554$ & $L=18.95$ \\
\hline
\end{tabular}

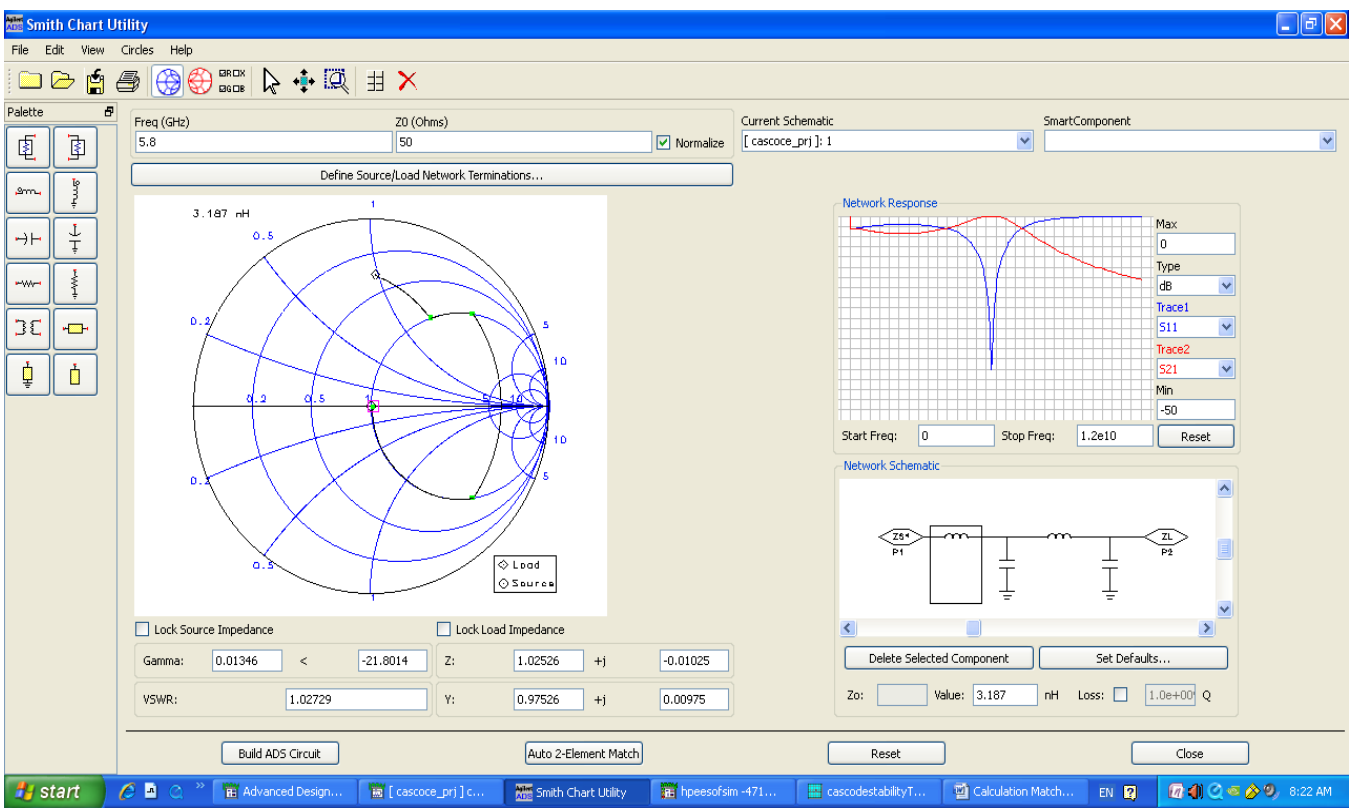

Fig. 4(a). The ladder matching network for input. 


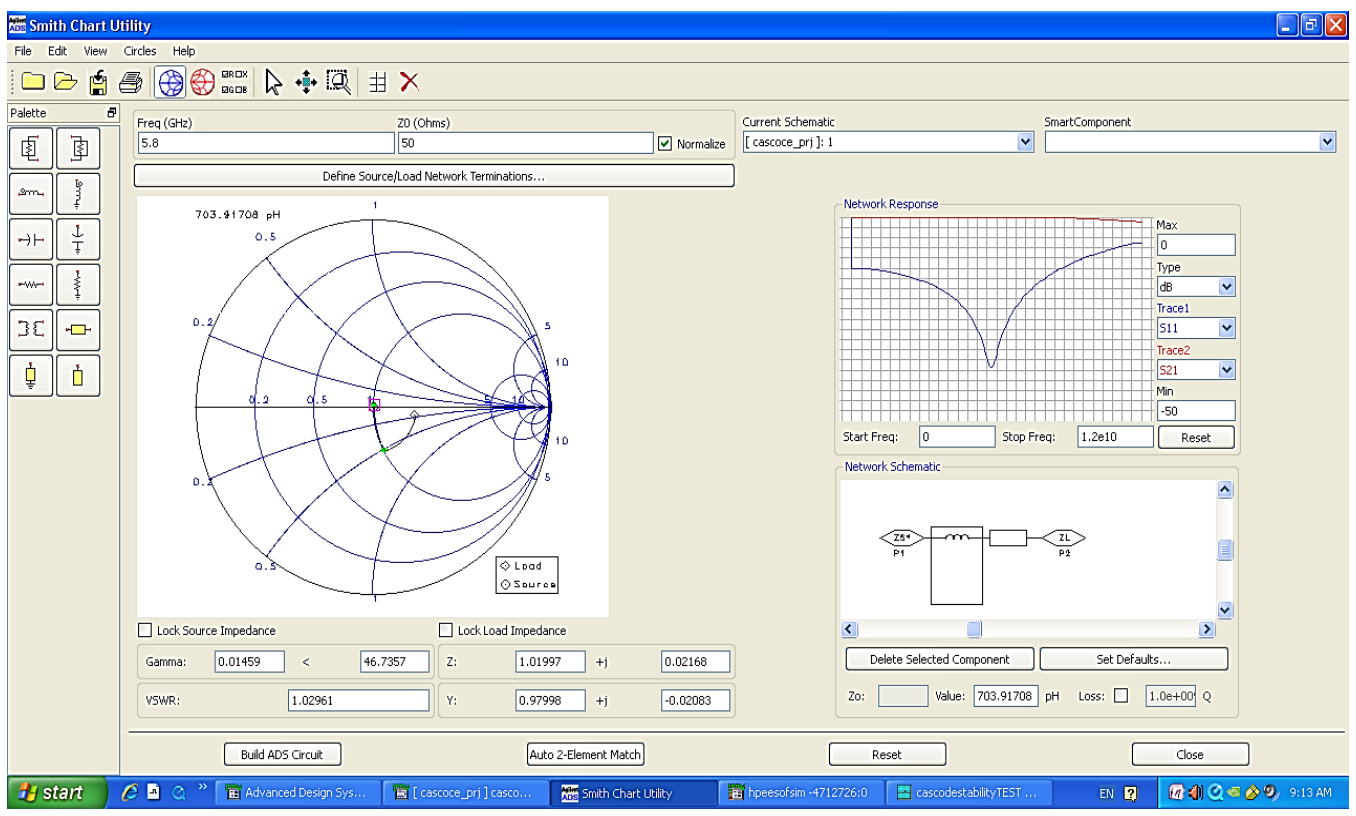

Fig. 4(b). The matching network for output.

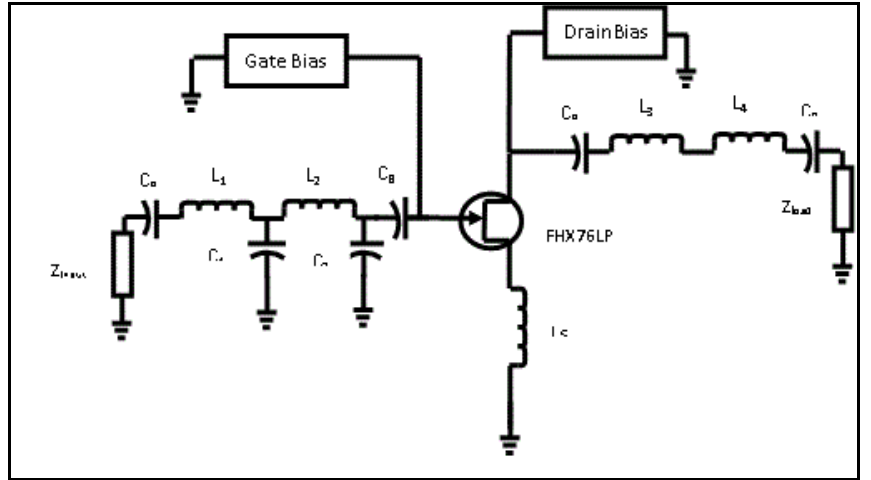

Fig. 5(a). The schematic circuit for LNA.

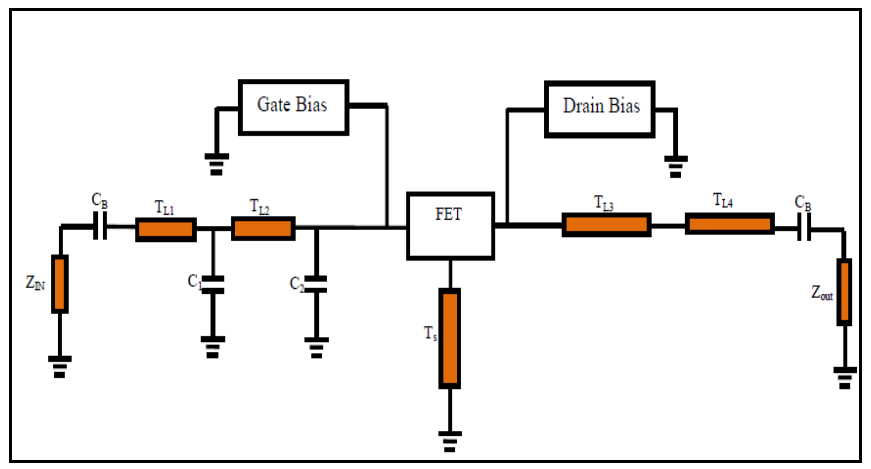

Fig. 5(b). The schematic layout for LNA.

\section{Simulation Result}

The simulated results of S-Parameter output of the LNA are shown in Fig. 6. It is simulated using Advanced Design System (ADS). The simulation recorded that the power gains $S_{21}$ is $17.2 \mathrm{~dB}$. The input return loss $S_{11}$ is $-18.9 \mathrm{~dB}$; overall noise figure (NF) of $0.914 \mathrm{~dB}$ and the output return loss $S_{22}$ is $-19.6 \mathrm{~dB}$. The reflection loss $S_{12}$ is $-19.9 \mathrm{~dB}$. These values were within the design specification and were accepted. Fig. 6(a) shows the forward transfer and output return loss. While, Fig. 6(b) shows the input reflection and the output reflection loss. Fig. 6(c) and Fig. 6(d) are shows the noise figure and stability Factor respectively.

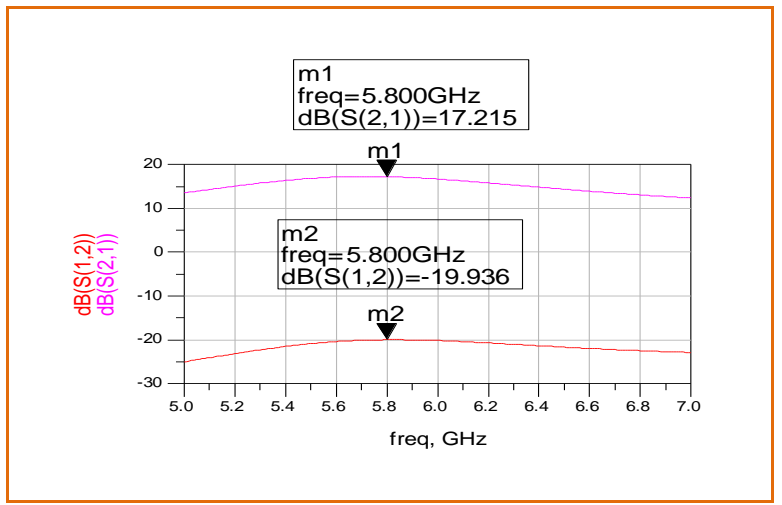

Fig. 6(a). $S_{21}$ and $S_{12}$.

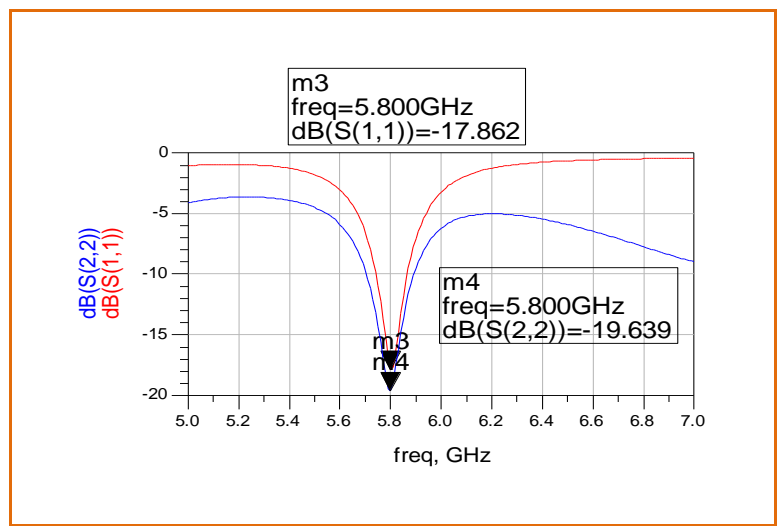

Fig. 6(b). $S_{11}$ and $S_{22}$.

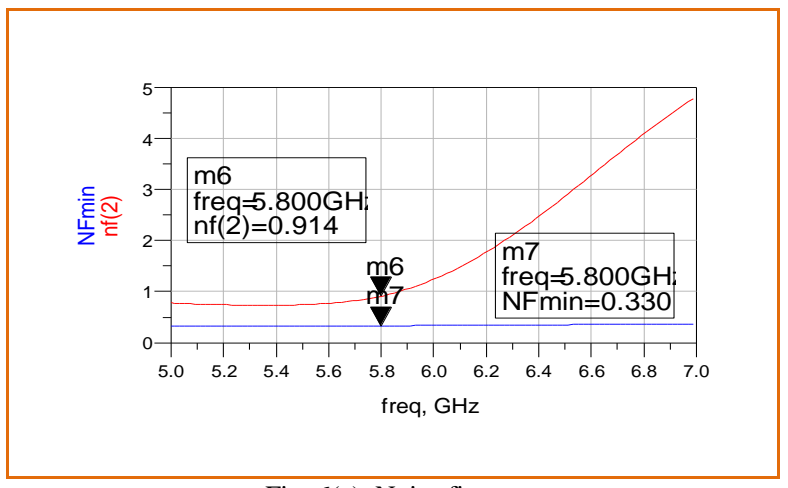

Fig. 6(c). Noise figure. 


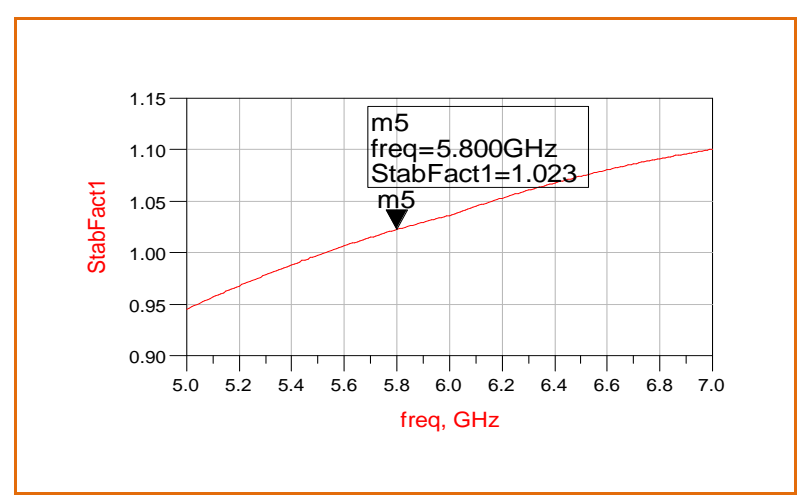

Fig. 6(d). Stability factor.

\section{CONCLUSION}

The low noise amplifier with ladder matching network has been simulated and designed. It's observed to compliant with IEEE standard 802.16 WiMAX application. It is observed that the simulated and targeted results giving almost the same figure as required. It observed that the gain of the simulated analysis is $17.2 \mathrm{~dB}$. It is important to take note when designing the amplifier to match the amplifier circuits. For better performance in gain of the amplifier, it can be achieved by increasing the number of stages to improve the gain and noise figure of the design [9], [10]. Higher gain would expand the coverage or communication distance.

\section{ACKNOWLEDGMENT}

The authors would like to take this opportunity to thank the Research Management \& Innovation Centre (RMIC) of Sultan Idris Education University for permitting and supporting in this research (2015-0052-104-01).

\section{REFERENCES}

[1] M. Steer, Microwave and RF Design: A System Approach, International Edition, 2010.

[2] R. L. Wang, S. C. Chen, C. L. Huang, C. H. Liu, and Y. S. Lin, "2-6 $\mathrm{GHz}$ current-reused LNA with transformer-type inductors," in Proc. 2008 APMC, IEEE, 2008.
[3] C. P. Chang, W. C. Chien, C. C. Su, Y. H. Wang, and J. H. Chen, "Linearity improvement of cascode CMOS LNA using a diode connected NMOS transistor with a parallel RC circuit," Progress in Electromagnetics Research C., vol. 17, pp. 29-38, 2010.

[4] M. A. G. L. Leon and G. D. M. Theresa, "Comparison of LNA topology for Wimax application in a standard 90-nm CMOS process," in Proc. 12th International Conference on Computer Modelling and Simulation, 2010, pp. 642-647.

[5] D. M. Pozar, "Microwave and RF wireless system," Third Avenue, N. Y. John Wiley \& Sons, 2001

[6] G. Gonzalez, "Microwave transistor amplifier," 1996.

[7] A. B. Ibrahim, A. R. Othman, M. N. Husain, M. S. Johal, and J. S. Hamidon, "The cascode LNA with RF amplifier at $5.8 \mathrm{GHz}$ using t-matching network for WiMAX applications," Journal of Telecommunication Electronic and Computer Engineering, vol. 4, no. 1, pp. 15-21, 2012.

[8] T. Van Hoi, N. X. Truong, and B. G. Duong, "Design and fabrication of high gain low noise amplifier at $4 \mathrm{GHz}$," International Journal of Engineering and Innovation Technology, vol. 4, no. 7, 2015.

[9] IEEE Computer Society and IEEE Microwave Theory Technique and Society, Part 16 Air Interface For Fix Broadband Wireless System, IEEE Standard 802.16.2004

[10] I. Bahl, "Fundamentals of RF and microwave transistor amplifier," 2009.

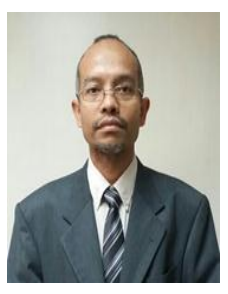

Abu Bakar Ibrahim received the B.S degree in electrical engineering and master degree from Universiti Teknologi Malaysia in 1998 and 2000, respectively. He received the $\mathrm{PhD}$ degree in electronic engineering (communication) from Universiti Teknikal Malaysia Melaka, 2013. His research interest includes the development of low noise amplifier, radio frequency communication system, instructional technology, engineering technology and engineering education. Now, he is working at Sultan Idris Education University of Malaysia.

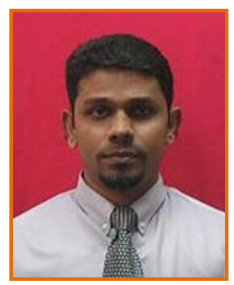

Ahmad Zamzuri Mohammad Ali received a B.S degree in electrical engineering and master degree of Universiti Teknologi Malaysia, in 1998 and 2000 respectively. He received the $\mathrm{PhD}$ degree in multimedia (education) from Universiti Sains Malaysia. His interests include the multimedia design, intructional technology, ICT in education, open source education and user interaction. Now he joined Sultan Idris Education of University Malaysia. 